\title{
El acompañamiento de hijos y familiares a la consulta médica no constituye un deber inexcusable de carácter público y personal que genere permiso retribuido.
}

\author{
Carmen Viqueira Pérez \\ Catedrática de Derecho del Trabajo y de la Seguridad Social. Universidad de Alicante
}

Resumen: Al hilo del análisis de la licitud de la normativa empresarial acerca del disfrute de las vacaciones y los permisos, la sentencia resuelve que el acompañamiento a los servicios sanitarios de determinados familiares (menores $y$ familiares no autosuficientes) no constituye para el trabajador el cumplimiento de un deber inexcusable de carácter público y personal y, por ende, no genera el permiso regulado en el art. 37.3.d ET.

Palabras clave: Permiso. Conciliación. Hijos. Deber inexcusable.

Abstract: Summary: In line with the analysis of the legality of the entrepreneurial regulations about the enjoyment of vacation and permissions, the judgment resolves that the accompaniment of certain family members (minors and non-self-sufficient family members) to the health services does not constitute for the worker an inexcusable public and personal duty and, therefore, does not generate the permission regulated in art. $37.3 E T$.

Keywords: Permission. Conciliation. Sons. Imperative duty.

\section{Introducción}

Entender que la necesidad del trabajador de acompañar a la consulta médica a determinados familiares (menores y familiares no autosuficientes) constituye una obligación equiparable a ese deber personal y público de cumplimiento inexcusable al que hace referencia el art. 37.3.d ET ha sido una cuestión debatida en la doctrina judicial que, partiendo de la base común de que el permiso retribuido que contempla el ET exige la concurrencia de las tres notas que lo definen (que el deber sea inexcusable, que tenga carácter público y naturaleza personal), en algunas ocasiones ha encontrado elementos en los que apoyarse para apreciar esta triple naturaleza, en tanto que en otras ha mantenido la imposibilidad de que estas notas concurran en este tipo de obligación o deber. EI TS apunta en esta última dirección al considerar que los deberes surgidos de las obligaciones familiares y de cuidados que regula el código civil -como sería el de acompañar al médico a un menor- no son obligaciones de carácter público ni obligan a una prestación personalísima ni insustituible.

II. Identificación de la resolución judicial comentada

Tipo de resolución judicial: sentencia.

Órgano judicial: Tribunal Supremo (Sala de lo Social). 
Número de resolución judicial y fecha: sentencia núm. 1098/2020, de 9 de diciembre.

Tipo y número recurso o procedimiento: Recurso casación ordinaria núm. 79/2019.

ECLI:ES:TS:2020:4478.

Fuente: CENDOJ.

Ponente: Excma Sra. Da. Maria Lourdes Arastey Sahún.

Votos Particulares: carece.

\section{Problema suscitado. Hechos y antecedentes}

La cuestión que la sentencia resuelve gira en torno a la licitud de una normativa interna del Banco de Sabadell que regula el disfrute de vacaciones y permisos, asunto del que, indirectamente, pende otro de más amplio alcance: los contornos del permiso para el cumplimiento de un deber inexcusable contenido en el art. 37.3.d ET.

El Banco de Sabadell cuenta con una normativa interna -denominada "Política $n^{\circ}$ 7378. Vacaciones y licencias"- en la que se regula el régimen de devengo y disfrute de las vacaciones, los permisos -retribuidos o no- y las ausencias -justificadas y sin justificar-. En el apartado "permisos no retribuidos" se establece que el trabajador podrá disfrutar de un "permiso para el acompañamiento a los servicios de asistencia sanitaria de hijos/hijas menores de 14 años y de parientes mayores de primer grado de consanguinidad o afinidad que no puedan valerse por sí mismos, por el tiempo indispensable. Por tratarse de permisos no retribuidos, el trabajador/trabajadora y la empresa podrán establecer mecanismos de compensación horaria".

Esta reglamentación empresarial reproduce de manera casi textual lo establecido en el convenio aplicable en la empresa (XXIII Convenio Colectivo de Banca) que, en su art. 33.1, establece que "se concederá permiso para el acompañamiento a los servicios de asistencia sanitaria de hijos o hijas menores de catorce años y de familiares mayores de primer grado de consanguinidad y afinidad que no puedan valerse por sí mismos. En estos supuestos, por tratarse de permisos no retribuidos, podrán establecerse mecanismos de compensación horaria".

En este contexto, en una reunión de la Comisión para la igualdad de oportunidades del Banco de Sababell celebrada en mayo 2018, la representante del sindicato ALTA sugiere una revisión de la reglamentación empresarial referida a los permisos en el sentido de que no sea preciso compensar el tiempo invertido en acompañar al médico a los hijos menores, argumentando que la inclusión de este tipo de medidas en los Planes de Igualdad ha sido ya refrendada en algunas sentencias y que es responsabilidad de todos los integrantes de la Comisión hacer lo necesario para lograrlo.

Unos meses después (octubre 2018), cambiando el plano de su reivindicación, el sindicato ALTA presentó demanda de conflicto colectivo ante la sala de lo social de la Audiencia Nacional solicitando la declaración de nulidad de la reglamentación empresarial en lo referente al permiso en cuestión, alegando que su regulación es contraria a lo establecido en el artículo 37.3.d ET porque acompañar al médico a un menor o a un familiar mayor dependiente es un deber inexcusable de carácter público y personal que, como se sabe, da lugar al disfrute de un permiso retribuido.

La demanda fracasa al estimar la Audiencia Nacional la excepción de inadecuación de procedimiento, al entender la Sala que éste no tiene por objeto la impugnación de un acto aplicativo del convenio (art. 163.4 LRJS) sino la modificación de una norma convencional cuya ilegalidad no se aduce ni sostiene en la demanda.

Frente a la desestimación, formula el sindicato ALTA recurso de casación sobre el fondo de asunto: solicitando la declaración de nulidad de la reglamentación 
empresarial del permiso para acompañamiento al médico de determinados familiares (hijos menores y familiares mayores e impedidos) por entender que éste tiene carácter retribuido al resultar incardinable en el art. 37.3.d ET.

\section{Posición de las partes}

El sindicato (ALTA) mantiene que la reglamentación empresarial del permiso es ilícita y debe declararse nula ya que, si bien no contraría la regulación del convenio colectivo aplicable -que, en su artículo 29, regula las "licencias retribuidas" sin referirse a este permiso-, vulnera el art. 37.3.d ET que reconoce el carácter retribuido de los permisos que tengan por objeto el cumplimiento de un deber inexcusable de carácter público y personal, coordenadas en las que cabe incluir el acompañamiento al médico de determinados familiares. La práctica de la empresa -derivada de esa reglamentación interna- resultaría contraria a lo establecido en el ET cuya regulación, obviamente, habría de venir a sustituir a la normativa interna convirtiendo así un permiso configurado como no retribuido en un permiso retribuido.

El argumentario de la empresa, por su parte, comienza por "negar la mayor", manteniendo la licitud de la reglamentación de la empresa por cuanto que ésta se ajusta a lo establecido tanto en el convenio colectivo (art. 33) como en el Plan de Igualdad de la empresa, instrumentos ambos en los que se establece que el acompañamiento a menores y dependientes para recibir asistencia sanitaria origina un derecho de ausencia no retribuido y compensable. Por lo demás, la empresa solicitó inicialmente que se impusiera a ALTA una sanción por temeridad que la Audiencia Nacional descarta por entender que la tesis mantenida no resulta jurídicamente insostenible y porque el sindicato no suscribió el Convenio Colectivo.

\section{Normativa aplicable al caso}

Inicialmente habrá de tenerse en cuenta el tenor literal de la reglamentación empresarial en torno a cuya eventual licitud arranca el litigio: "Política $n^{\circ} 7378$. Vacaciones y licencias"- que en el apartado "permisos no retribuidos" establece que el trabajador podrá disfrutar de un "permiso para el acompañamiento a los servicios de asistencia sanitaria de hijos/hijas menores de 14 años y de parientes mayores de primer grado de consanguinidad o afinidad que no puedan valerse por sí mismos, por el tiempo indispensable. Por tratarse de permisos no retribuidos, el trabajador/ trabajadora y la empresa podrán establecer mecanismos de compensación horaria".

También han de considerarse los artículos 29 y 33 del XXIII Convenio Colectivo de Banca (BOE 15 junio 2016):

Art. 29. Licencias.

1. Las Empresas, a solicitud de su personal, concederá las siguientes licencias retribuidas, siempre que no excedan de quince días al año:

a) Por matrimonio del trabajador o la trabajadora: 15 días ininterrumpidos.

b) Por matrimonio de ascendientes, descendientes o colaterales hasta el tercer grado: el día en que se celebre la ceremonia.

c) Dos días laborables por nacimiento de hijo o hija que se tomarán inmediatamente a continuación del mismo y adicionalmente un día más de licencia a disfrutar dentro de los 30 días siguientes a la fecha del nacimiento.

d) Dos días por fallecimiento, accidente o enfermedad graves u hospitalización de parientes hasta el segundo grado de consanguinidad o afinidad. En el caso de fallecimiento de descendientes la licencia será de cinco días. Cuando por tales motivos se necesite hacer un desplazamiento que obligue a pernoctar fuera de su localidad, la licencia se ampliará hasta dos días más. 
e) Por fallecimiento de cónyuge: tres días laborables, que podrán ampliarse en dos días naturales más cuando se tenga que hacer un desplazamiento que obligue a pernoctar fuera de su localidad.

f) Por mudanza (incluso las que se realicen dentro de una misma localidad): dos días, salvo cuando se trate de traslado a/o desde localidades situadas fuera de la Península, en cuyo caso la licencia será de tres días.

La licencia por matrimonio no computará a efectos del límite a que se refiere el párrafo primero de este mismo apartado.

Se reconocen a las parejas de hecho las mismas condiciones que al matrimonio en la aplicación de este artículo. A estos efectos, la existencia o constitución de pareja de hecho se acreditará mediante certificación de la inscripción en alguno de los registros específicos existentes en las Comunidades Autónomas o Ayuntamientos del lugar de residencia o mediante documento público en el que conste la constitución de dicha pareja".

\section{Artículo 33. Licencias y excedencias para cuidado de familiares}

1. Se concederá permiso para el acompañamiento a los servicios de asistencia sanitaria de hijos o hijas menores de catorce años y de familiares mayores de primer grado de consanguinidad y afinidad que no puedan valerse por sí mismos. En estos supuestos, por tratarse de permisos no retribuidos, podrán establecerse mecanismos de compensación horaria.

2. El personal tendrá derecho a un período de excedencia de duración no superior a tres años para atender al cuidado de cada descendiente, tanto lo sea por naturaleza como por adopción o en los supuestos de acogimiento, tanto permanente como preadoptivo aunque éstos sean provisionales, a contar desde la fecha de nacimiento o en su caso, de la resolución judicial o administrativa.

3. También se tendrá derecho a un período de excedencia no superior a dos años para atender al cuidado de familiares hasta el segundo grado de consanguinidad o afinidad, que por razones de edad, accidente, enfermedad o discapacidad no pueda valerse por sí mismo y no desempeñe actividad retribuida.

El período en que el personal permanezca en situación de excedencia conforme a lo establecido en este apartado, será computable a efectos de antigüedad y se tendrá derecho a la asistencia a cursos de formación profesional, a cuya participación deberá ser convocado por la Empresa, especialmente con ocasión de la reincorporación. Durante el primer año se tendrá derecho a la reserva de su puesto de trabajo. Transcurrido dicho plazo la reserva quedará referida a un puesto de trabajo del mismo grupo profesional.

En caso de familia numerosa se estará a lo dispuesto en cada momento en el Estatuto de los Trabajadores (actualmente artículo 46.3).

Como complemento a la normativa de origen convencional, será igualmente necesario considerar la regulación contenida en el Plan de Igualdad que, en el apartado correspondiente a la Conciliación de la vida familiar y laboral, regula la "Licencia no Retribuida para Acompañamiento de Hijos/Hijas o Familiares Mayores de Primer Grado a los servicios de asistencia sanitaria" en estos términos: "Según establece el artículo 33.1 del CCB, se concede permiso no retribuido para el acompañamiento a los servicios de asistencia sanitaria de hijas o hijos menores de 14 años y de familiares mayores de primer grado de consanguinidad o afinidad que no puedan valerse por sí mismos, pudiéndose establecer mecanismos de compensación horaria”. (El límite de edad sería posteriormente rebajado a 12 años)

Por otra parte, es normativa aplicable al caso el art. 37.3.d ET: "El trabajador, previo aviso y justificación, podrá ausentarse del trabajo, con derecho a remuneración, por alguno de los motivos y por el tiempo siguiente: (...) d) Por el tiempo 
indispensable, para el cumplimiento de un deber inexcusable de carácter público y personal, comprendido el ejercicio del sufragio activo. Cuando conste en una norma legal o convencional un periodo determinado, se estará a lo que esta disponga en cuanto a duración de la ausencia y a su compensación económica. Cuando el cumplimiento del deber antes referido suponga la imposibilidad de la prestación del trabajo debido en más del veinte por ciento de las horas laborables en un periodo de tres meses, podrá la empresa pasar al trabajador afectado a la situación de excedencia regulada en el artículo 46.1. En el supuesto de que el trabajador, por cumplimiento del deber o desempeño del cargo, perciba una indemnización, se descontará el importe de la misma del salario a que tuviera derecho en la empresa".

Y, finalmente, han de considerarse también los art. 110; 142 y 143 del código civil:

Art. 110 CC. "El padre y la madre, aunque no ostenten la patria potestad, están obligados a velar por los hijos menores y a prestarles alimentos"

Art. 142 CC: "Se entiende por alimentos todo lo que es indispensable para el sustento, habitación, vestido y asistencia médica".

Art. 143 CC: "Están obligados recíprocamente a darse alimentos en toda la extensión que señala el artículo precedente: 1. Los cónyuges. 2. Los ascendientes y descendientes".

\section{Parte dispositiva}

La sentencia comentada, -STS 1098/2020 (Rec. 79/2019)- desestima el recurso de casación planteado por el sindicato ALTA (al que se adhiere el sindicato SICAM/ Sabadell) frente a la sentencia de la Sala de lo Social de la Audiencia Nacional de 13/12/2018 (autos núm. 295/2018). A diferencia de la resolución recurrida, que desestima la demanda al apreciar la excepción de inadecuación de procedimiento, la sentencia del Alto Tribunal desestima el recurso por razones de fondo.

Así, la sentencia concluye que "aunque no acabamos de compartir la formulación que hace la sentencia al considerar que el litigio se hallaba planteado de forma inadecuada, sí es cierto que la demanda estaba pretendiendo modificar una condición de trabajo que se acomoda perfectamente al marco normativo existente $y$, en ese sentido, la conclusión que se alcanza es que dicha demanda debe de ser desestimada. La parte actora planteó una pretensión de conflicto colectivo que ha de rechazarse por razones de fondo, sin que quepa la remisión a ninguna otra modalidad procesal, por ello, la absolución de la empresa en el fallo de instancia se corresponde con la desestimación de la demanda".

Por lo que hace al fondo del asunto, la sentencia, de entrada, asevera que "la práctica de la empresa en relación con dicho permiso (...) resulta coincidente con el texto convencional con literalidad milimétrica" de modo que "la primera conclusión que debemos extraer es que la empresa en modo alguno ha infringido una norma imperativa como es la que resulta del convenio" sino que "estamos ante un supuesto de mantenimiento y aplicación de una condición laboral en los propios términos del convenio que la establece".

En consecuencia, señala que "ni la práctica empresarial impugnada contraviene la norma de rango legal, ni cabría tildar de ilegalidad a la cláusula del convenio" porque el permiso convencionalmente regulado no resulta incardinable en el supuesto contemplado en el art. 37.3.d ET (cumplimiento de un deber inexcusable) dado que "el permiso regulado en la norma legal transcrita está vinculado a la existencia de un deber de la persona trabajadora que reúna todas y cada una de las siguientes características: a) que sea inexcusable; b) que sea de carácter público; y c) que sea de carácter personal" y ninguna de estas circunstancias concurre en el permiso de acompañamiento de menores o de parientes mayores a la consulta médica, ya que "los deberes surgidos de las obligaciones familiares y de cuidados -fruto de las relaciones de filiación (ex art.110 del Código Civil -CC-) o del deber de alimentos entre parientes en sentido amplio (ex art. 142 CC)-, a los que cabría ligar la actividad que 
genera el derecho al permiso aquí controvertido, no sólo no obligan a su prestación personalísima e insustituible de los deudores de los mismos, sino que difícilmente pueden ser configuradas como obligaciones de carácter público. Por el contrario, pertenecen al ámbito privado y familiar y, por ello, estamos ante un permiso alejado por completo de la previsión específica del art. 37.3 d) ET".

\section{Pasajes decisivos}

El hilo que estructura el discurso de la sentencia muestra una serie de pasajes decisivos que constituyen su andamiaje argumental.

El primero, incide de pleno a la pretendida laguna ("ausencia de tratamiento") de la que adolecería el Convenio colectivo con respecto a la regulación del permiso en cuestión porque aun cuando -como aduce el sindicato- su art. 29 no incluye este permiso el listado de "licencias retribuidas", sí lo hace en el art. 33.1 que se ocupa del mismo con todo detalle: "el convenio colectivo por el que se rigen las relaciones laborales de la empresa no contiene el controvertido permiso entre las "licencias retribuidas", las cuales se regulan por el mencionado art. 29. La parte recurrente afirma que hay una "ausencia de tratamiento" del indicado permiso en el convenio y, por ello, considera que la mera aplicación del art. 37.3 d) ET basta para sostener su carácter retribuido. Sin embargo, la premisa sobre la que se construye el silogismo anterior es completamente errónea. El art. 33.1 del Convenio dispone: "Se concederá permiso para el acompañamiento a los servicios de asistencia sanitaria de hijos o hijas menores de catorce años y de familiares mayores de primer grado de consanguinidad $y$ afinidad que no puedan valerse por sí mismos. En estos supuestos, por tratarse de permisos no retribuidos, podrán establecerse mecanismos de compensación horaria".

Consecuencia de ello -y este sería otro pasaje a destacar- es que la normativa interna de la empresa cuenta con el decisivo respaldo de la regulación convencional: "El permiso para acompañamiento sanitario, objeto del conflicto, no sólo tiene tratamiento expreso en el Convenio colectivo aplicable, sino que es éste precisamente el que lo instauró y, por tanto, al que se debe su configuración. Y, es más, el convenio lo diseña claramente como un permiso no retribuido".

Es de destacar, a este respecto, que la sentencia se detiene a puntualizar cómo la empresa se ha limitado al cumplimiento estricto del convenio sin haber dado lugar al nacimiento de ninguna condición más beneficiosa que permitiera mantener, a su través, el carácter retribuido del permiso y así señala que "el permiso que el convenio establece no tiene carácter retribuido y la realidad de la práctica en el seno de la empresa se ajusta de modo estricto a esa misma característica -como también lo hace respecto al resto de elementos que definen el permiso-. Nótese que en este caso no se plantea la cuestión de que en algún momento la plantilla de la demandada hubiera disfrutado de una mejora respecto del mínimo convencional, que ahora pudiéramos estar ante una modificación susceptible de ser tachada de injustificada. Insistimos, pues, en que estamos ante un supuesto de mantenimiento y aplicación de una condición laboral en los propios términos del convenio que la establece".

Sentado que la normativa empresarial se acomoda a lo establecido en el convenio colectivo, la sentencia aborda la cuestión de si esa previsión contraviene lo establecido en el art. 37.3.d ET y si, por ende, la cláusula convencional tendría que tacharse de ilegal por ese mismo motivo. Dicho de otro modo, se cuestiona si la necesidad de acompañar al médico a determinados familiares (menores o mayores que no pueden valerse por si mismos) puede considerarse un "deber inexcusable de carácter público y personal" de los que sustentan el permiso retribuido que regula el art. 37.3.d ET, afirmando que "el permiso regulado en la norma legal transcrita está vinculado a la existencia de un deber de la persona trabajadora que reúna todas y cada una de las siguientes características: a) que sea inexcusable; b) que sea de carácter público; y c) que sea de carácter personal. Los deberes surgidos de las obligaciones familiares y de cuidados -fruto de las relaciones de filiación (ex art.110 del Código Civil -CC-) o del deber de alimentos entre parientes en sentido amplio (ex art. 142 CC)-, a los que cabría ligar la actividad que genera el derecho al permiso aquí controvertido, no sólo 
no obligan a su prestación personalísima e insustituible de los deudores de los mismos, sino que difícilmente pueden ser configuradas como obligaciones de carácter público. Por el contrario, pertenecen al ámbito privado y familiar y, por ello, estamos ante un permiso alejado por completo de la previsión específica del art. 37.3 d) ET".

\section{Comentario}

Tal y como se ha apuntado ya, la sentencia comentada -amen de refrendar la licitud de la normativa interna de la empresa que recoge lo que el convenio colectivo establece- clarifica los contornos que definen el permiso previsto en el art. 37.3.d ET para el cumplimiento de un deber inexcusable de carácter público y personal en el que, a juicio del TS, no encuentra encaje la necesidad que el trabajador pueda tener de acompañar al médico a determinados familiares.

Entender que la necesidad del trabajador de acompañar a la consulta médica a determinados familiares (menores y familiares no autosuficientes) constituye una obligación equiparable a ese deber personal y público de cumplimiento inexcusable al que hace referencia el art. 37.3.d ET ha sido una cuestión debatida en la doctrina judicial que, partiendo de la base común de que el permiso retribuido que contempla el ET exige que el deber sea inexcusable; que sea de carácter público y que tenga naturaleza personal, en algunas ocasiones ha encontrado elementos en los que apoyarse para apreciar esta triple naturaleza en tanto que en otras ha mantenido la imposibilidad de que concurran en este tipo de obligación o deber.

Como exponente de la primera línea interpretativa suele citarse la STSJ de Galicia $(17 / 06 / 2011)$ en la que se mantiene que la obligación de los padres por velar de los hijos menores establecida en el art. 110 del código civil presenta ese carácter personal (por cuanto que se encomienda a los padres) y constituye un deber "tuitivo insoslayable con un matiz público evidente" al venir impuesto por una norma -el código civil- (argumento al que en ocasiones se añade la idea de que esta regulación cuenta con proyección constitucional habida cuenta de que el artículo 39.2 CE establece como principio rector de la política social la protección integral de los hijos).

Frente a esta postura se abre paso la posición (avanzada en la STSJ de Galicia 14/07/2017 y la STSJ de Canarias 27/02/2017) que refrenda la sentencia comentada: que el permiso contenido en el art. 37.3.d ET descansa sobre tres elementos de perfil estricto que no es posible apreciar en la obligación del trabajador de acompañar al médico a determinados familiares.

Así, los deberes derivados de las obligaciones familiares y de cuidados que establece para los padres el art. $110 \mathrm{CC}$ con respecto a los hijos menores y el deber de alimentos que -en sentido amplio- se establece en los art. 142 y 143 CC con respecto a determinados parientes (cónyuges, ascendientes o descendientes) son obligaciones que se generan en (y pertenecen a) el ámbito privado y familiar sin que el hecho de que vengan reguladas en el código civil las convierta en deberes de carácter público, requisito que suele identificarse con el hecho de que el deber en cuestión venga impuesto por la Administración pública o por un poder público (o bien de aquellos que vengan calificados como tales por una norma -como es el caso de la donación de sangre -RD 1088/2005- o por la reglamentación interna de la empresa STSJ Comunidad Valenciana 16/06/2015-).

Tampoco el hecho de que los padres tengan el general deber de cuidar de sus hijos implica que cualquier manifestación de este deber -como es el caso de acompañarlos al médico- tenga carácter personal, por cuanto que acompañar a un menor o a un familiar al médico no encierra una prestación personalísima e insustituible sino una obligación de hacer que puede ser cumplida por otras personas. $Y$ algo parecido cabe decir con respecto al carácter inexcusable que ha de caracterizar el deber para sustentar el permiso retribuido porque la "inexcusabilidad" se predica de los deberes impuestos por el ordenamiento jurídico cuyo incumplimiento hace incurrir en responsabilidad. 
La sentencia, por todo ello, concluye -acertadamente, a mi juicio- que acompañar a determinados familiares a una consulta médica no es una actividad identificable como un "deber inexcusable de carácter público y personal" cuyo cumplimiento justifique el disfrute del permiso retribuido regulado en el art. 37.3.d ET.

\section{Apunte final}

Más allá de que la conclusión alcanzada en la sentencia resulte ser -a mi juicio- la jurídicamente correcta, la cuestión que en ella se aborda evidencia hasta qué punto asuntos tan habituales como acompañar a un hijo menor -o a un familiar no autosuficiente- a la consulta médica se encuentran huérfanos de un tratamiento adecuado y/o suficiente. Es cierto que -especialmente en los últimos años- el legislador ha acometido con decisión la tarea de articular un panorama razonablemente completo de medidas tendentes a la conciliación de la vida familiar y laboral pero también es evidente que la negociación colectiva está llamada a reforzar ese marco y/o, en su caso, completar las lagunas de las que la norma pueda adolecer. En este sentido, la sentencia viene a poner en primer plano el papel crucial que el convenio puede y debe cumplir en este sentido. 